\title{
Case Article
}

\section{Psyllium Together with Allopurinol Can Efficiently Reduce the Increased Serum Level of Uric Acid, Creatinine and Urea: A Case Report}

\author{
Alireza Ebadollahi-Natanzi ${ }^{* 1}$, Gholamreza Arab-Rahmatipour ${ }^{2}$
}

Accepted: 05.04.2017

\section{ABSTRACT}

Background: Medicinal plants have potential to affect therapeutically procedures. In this study, the therapeutical effects of psyllium on a patient with highly increased level of uric acid, creatinine, and urea have been studied.

Case Report: The case was a 50-yr-old woman affected by diabetes mellitus. Her blood biochemical analyses, showed an increased levels of uric acid $(9.70 \pm 0.30 \mathrm{mg} / \mathrm{dL})$, urea $(93.00 \pm$ $3.60 \mathrm{mg} / \mathrm{dL})$ and creatinine $(2.30 \pm 0.20 \mathrm{mg} / \mathrm{dL})$. She was taken allopurinol $(100 \mathrm{mg} /$ daily) followed by consumption of $5 \mathrm{gr} /$ daily from psyllium seeds which continued for two consecutive weeks. Then, the levels of uric acid, urea and creatinine were reached the normal value so that their measured levels were $5.60 \pm 0.26 ; 34.00 \pm 1.73$ and $1.10 \pm 0.10 \mathrm{mg} / \mathrm{dL}$, respectively. Psyllium together with allopurinol could also reduce cholesterol and triglyceride levels in this patient.

Conclusion: We can conclude that psyllium along with allopurinol can synergistically decrease the increased levels of uric acid, creatinine, and urea.

Keywords: Allopurinol, Creatinine, Psyllium, Urea, Uric Acid.

IJT 2017 (4): 51-56

\section{INTRODUCTION}

The incidence of some diseases such as diabetes, hyperlipidemia, and hyperuricemia is accompanied by fatness, low of movement, and gout or formed by genetically defects leading to increased use levels of drugs and medicines. However, sometimes the use of these drugs will be ensued by a series of side and adverse effects. Therefore, the global attention has been focusing on finding some medicine alternatives to decrease the adverse effects attributed to the use of synthetic drugs for the control of the abovementioned diseases. Since in medicinal plants, there are some active ingredients or compounds structurally accorded to bimolecular structures of human beings; therefore, it is possible that the adverse effects of medicinal plants can be less compared to synthetic drugs $[1,2]$.

Nowadays, the broad spectrum of therapeutically effects for medicinal plants has been reported including antibacterial, antiviral, anti-inflammatory, antioxidants, antihepatotoxic [3-8]. In most cases, the use of complementary and alternative medicines (CAM) is inevitable and this approach has been increasingly developed around the world. Additionally, sub-disciplinary treatment procedures dependent to CAM including homeopathy, acupuncture, and herbal medicine, can efficiently control some diseases [9].

Allopurinol has currently been used in treatment of some diseases such as gout and uric acid caused nephropathy. However, it causes to make some adverse effects such as hypersensitivity syndrome with a $20 \%$ mortality rate reported in few cases, gastrointestinal intolerance and rashes [10-12]. Therefore, all efforts are now focusing on finding an alternative medicine with natural based to reduce the mentioned adverse effects and also to be more efficient in patients having high levels of uric acid, urea and creatinine [13].

The plants Plantago psyllium and P. ovata Forsk belong to plantaginaceae family known as Esparzeh. Psyllium (Esparzeh) in Iran is an herbal plant. In traditional medicine it has been used for treatment of wounds and furthermore, its seeds can be used to treat gastro disturbance and

1. Department of Medicinal Plants, Imam Khomeini Higher Education Center Agriculture Research, Education and Extension Organization (AREEO), Karaj, Iran.

2. Department of Biochemistry, Farabi Hospital Laboratory, Tehran University of Medical Sciences, Tehran, Iran.

* Corresponding Author: E-mail: ebad@ihec.ir 
diseases caused by kidney and bladder systems inflammations [14]. It is also being used as laxative [15]. Psyllium' seeds have lowering effects on cholesterol and uric acid as well [16, 17].

In the present study, the therapeutic effects taken from psyllium plant along with allopurinol drug, in a patient with increased serum levels of uric acid, urea, and creatinine, have been investigated. The aim of this study was to reduce allopurinol dosage by adding psyllium to conventional treatment used for this patient to achieve lowering the side effects pertaining allopurinol drug.

\section{CASE REPORT}

In this report which was started in July 2012 and carried out in pathobiology laboratory of Farabi Hospital, a 50-yr-old woman affected by diabetes mellitus type 2 and used to take drug glibenclamide (5 $\mathrm{mg}$ tab; three times daily ) in combination with metformin drug (500 mg doses; two times daily) was examined. The patient was suffered from severe pain in her feet, accompanied with edema. The development of this edematous process in this patient was formed within one week. The initial blood levels of uric acid, urea and creatinine were measured several times and shown highly increased levels of these measured biochemical parameters in her serum so that for uric acid, urea and creatinine this levels reached $9.70 \pm 0.30,93.00 \pm 3.60$ and $2.30 \pm 0.20 \mathrm{mg} /$ $\mathrm{dL}$, respectively. The patient was diagnosed as hyperuricemia based on the uric acid level more than $7 \mathrm{mg} / \mathrm{dL}$ in accordance with disease categories defined by international classification diseases (ICD) [18].

Treatments, procedures and the aim of study were completely explained to the patient who gave her consent written for conducting this study. The protocol was performed based on the ethical principles considered for clinical laboratory assays.

\section{Treatment Protocol}

The framework of treatment was explained to the patient and based on her consensus the treatments were started. The patient was prescribed $100 \mathrm{mg}$ of allopurinol drug in a day based on physician discretion. She was also concurrently given the seeds of psyllium. Since in some before research carried out on psyllium has been shown it can effectively reduce the increased levels sugar and lipid in human serum at dose of 5 $\mathrm{g}$ in a day [16]; therefore, the treatment was started with $5 \mathrm{gr}$ of psyllium in $150 \mathrm{ml}$ of water to form complete mucilage of that. This treatment was kept on patient for two weeks. In order to avoid any further interference between psyllium and allopurinol, there was considered a one-hour delay interval. The patient was recommended on drinking the excess amount of drinking water (around $2 \mathrm{~L}$ in a day). The drug allopurinol was supplied by Jalinous Pharmaceutical Company (Tehran, Iran). Psyllium seeds were provided by local herbal shop.

\section{Laboratory Analyses}

The measuring uric acid, urea, creatinine, total cholesterol, and triglycerides in patient's blood were done before and after treatment by several times and in fasting status. After sampling, blood samples bearing tubes were kept incubated in lab ambient for the time between 30 to $40 \mathrm{~min}$. Then the samples centrifuged at speed $3500 \mathrm{rpm}$ for $10 \mathrm{~min}$ and the serum was separated from other blood constituents. The measurement of aforementioned biochemical parameters was done by quantitative analytical kit provided by Pars Azmun Company (Tehran, Iran). Photometric method was adopted for the whole analysed and the instrument of Selectra E was used for going through the experiments. TruLab $\mathrm{N}$ control serum was used as a control of accuracy and precision of tests. All tests were carried out in Pathobiology Laboratory of Farabi Hospital.

\section{Therapeutic Response}

Therapeutic evaluation was based on the changes in uric acid, urea, creatinine, total cholesterol and triglycerides in patient' $\mathrm{s}$ blood. Therapeutic response was indexed based on reversal of increased level of biochemical parameters to its normal one.

\section{DISCUSSION}

There was a significant difference in blood levels of analyzed biochemical parameters with the levels obtained from before treatment $(P<0.01)$. The mean levels of uric acid, urea, and creatinine before treatment were found to be $9.70 \pm 0.30,93.00 \pm 3.60$ and $2.30 \pm 0.20 \mathrm{mg} / \mathrm{dL}$, respectively. Whilst after treatment these levels were reduced and respectively equaled to $5.60 \pm$ 
$0.26,34.0 \pm 1.73,1.10 \pm 0.10 \mathrm{mg} / \mathrm{dL}$. The normal ranges considered for uric acid; urea and creatinine in women are $2.30-6.10 ; 17.0-43.0$ and $0.60-1.30 \mathrm{mg} / \mathrm{dL}$, respectively (Table 1 ). The reduced percentages of uric acid; urea and creatinine will be $42.27 \%, 63.44 \%$ and $52.17 \%$ when compared with the values of before treatment.

Table 1. The measurement of serum levels of biochemical parameters before and after concomitant treatment allopurinol and psyllium.

\begin{tabular}{cccccc}
\hline $\begin{array}{c}\text { Biochemical } \\
\text { parameters }\end{array}$ & $\begin{array}{c}\text { Urea } \\
(m g / d L)\end{array}$ & $\begin{array}{c}\text { Creatinine } \\
(m g / d L)\end{array}$ & $\begin{array}{c}\text { Uric Acid } \\
(m g / d L)\end{array}$ & $\begin{array}{c}\text { Cholesterol } \\
(m g / d L)\end{array}$ & $\begin{array}{c}\text { Triglycerides } \\
(m g / d L)\end{array}$ \\
\hline Before Treatment & $93.0 \pm 3.60$ & $2.30 \pm 0.20$ & $9.70 \pm 0.30$ & $194 \pm 4.00$ & $215 \pm 5.00$ \\
After Treatment & $34.0 \pm 1.73^{* * * *}$ & $1.10 \pm 0.10^{* *}$ & $5.60 \pm 0.26^{* * *}$ & $134 \pm 3.60^{* *}$ & $124 \pm 2.52^{* * * *}$ \\
Normal Range & $17-43$ & $0.7-1.40$ & $2.3-6.10$ & Up to 200 & Up to 200 \\
\hline
\end{tabular}

The data has been indicated as Mean \pm SD in three replicates. ** $P<0.01$; *** $P \leq 0.001$ when compared with pretreatment results.

The results obtained from cholesterol and triglycerides measurements showed that these two biochemical levels were put in normal range so that for cholesterol and triglycerides these values were $194 \pm 4.00$ and $215 \pm 5.00 \mathrm{mg} / \mathrm{dL}$, respectively (Figure 1). The values obtained from posttreatment procedures in this patient showed that the levels of cholesterol and triglycerides, under the influence of allopurinol drug and psyllium medicinal plant, have significantly reduced $(P<0.01)$ and reached up to $134 \pm 3.60 \mathrm{mg} / \mathrm{dL}$ and $124 \pm 2.52 \mathrm{mg} / \mathrm{dL}$ compared with before treatment. (Figure 1).

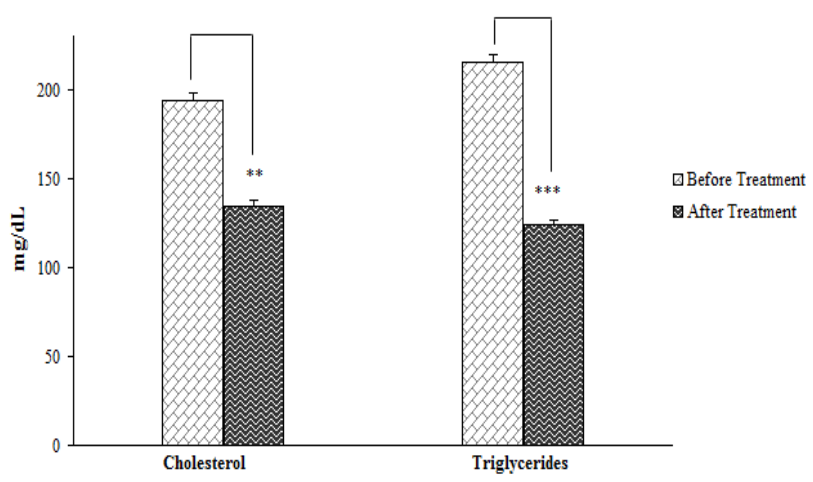

Figure 1. Comparison of cholesterol and triglycerides levels in undertreated patient before and after concomitant treatment allopurinol and psyllium. ** $P<0.01$; *** means $P<0.001$.

The measurement results of uric acid, creatinine blood levels in this patient before treatment have been shown in Figure 2. The levels of uric acid and creatinine were found to be $9.70 \pm 0.30$ and $2.30 \pm 0.20 \mathrm{mg} / \mathrm{dL}$, respectively. Significant reductions in levels of these two parameters after treatment were seen $(P<0.01)$. The values for uric acid and creatinine were measured as $5.60 \pm 0.26$ and $1.10 \pm 0.10 \mathrm{mg} / \mathrm{dL}$ (Figure 2). The mean levels of urea before and after treatment were also measured. The urea levels in this patient significantly reduced after concurrent use of psyllium and allopurinol $(P<0.001)$.

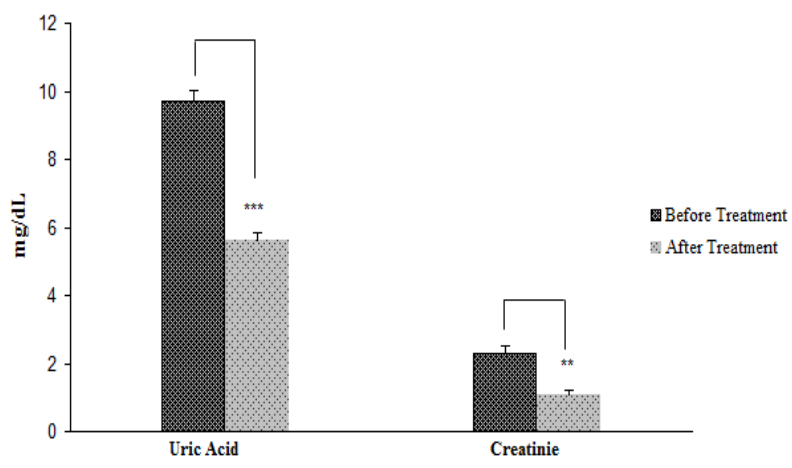

Figure 2. The measurement of uric acid and creatinine levels in hyperuricemic patient before and after concomitant treatment allopurinol and psyllium. $* * P<0.01$; *** means $P<0.001$.

After ending the treatment period, the patient symptoms including severe pain and the presence of edema in feet were completely disappeared. The reduced levels of biochemical parameters after applying these kinds of treatments showed that the adapted therapeutic protocol could put an effect on this patient (Table 1). This result confirming this matter that, the use of Iranian herbal medicine namely esparzeh and the synthetic drug of allopurinol have synergistically effect and they are together able to 
control hyperuricemia developed in this patient. Additionally, this concomitant use of herbal and chemical drugs could significantly reduce the serum levels of cholesterol and triglycerides. This result accords to some reports in shown psyllium together with some ordinary used blood glucose levels reducing drugs are able to attenuate the increased levels of lipids and glucose in type 2 diabetic patients [19]. Psyllium can be used as adjunct components in lipid reducing of blood levels in human; however, finding the exact dosage and also its therapeuticall dependant period will be needed to some further and complementary research.

The putative mechanism considered for allopurinol drug is through inhibition of xanthine oxidase (XO) enzyme [20,21]. The enzyme XO is a source of oxygen radicals in many of human tissue cells and it is able to produce superoxide $\left(\mathrm{O}_{2}{ }^{-}\right)$and peroxide radical $\left(\mathrm{O}_{2}{ }^{.2-}\right)$ [22]. In fact, allopurinol can prevent the conversion of hypoxanthine to xanthine and xanthine to uric acid and in this way; it can be useful for treatment of some diseases such as gout and hyperuricemia [21].

Some herbal medicinal plants, due to the presence of some compounds like flavonoids can remove free radicals in vitro and/ or by the presence flavonoid compounds in their components, have inhibitory effects of $\mathrm{XO}$ enzyme [20, 23, 24]. In this regard, the psyllium plant constitutes some kind of glycosides (iridoid glycosides) named aucubin and a carbohydrate backbone under the name of xylan. The activity of aucubin is similar to the substance acetylcholine, and aucubin together with caffeic acid and chlorogenic acid have anti-leukemic activities [25]. Plantago seeds are believed to have high potential for antioxidant properties and antiinflammatory effects [26]. It may be one of the reasons could help the patient to overcome the developed edema in her feet and improving the severity of her pain.

The high antioxidant level present in psyllium mostly appeared as luteolin flavonoid as well as terpenoids (oleanolic acid, ursolic acid, and linalool), may have involved in reducing the pre mediators for synthesis of inflammatory mediates like leukotrienes [26, 27]. However, among the aforementioned components, the role of luteolin is more prominent in psyllium plant for $\mathrm{XO}$ inhibition; so that luteolin lonely or, in conjunction with other plant constituents such as epigallocatechin, could efficiently inhibit XO enzyme which is approximately as potent as allopurinol drug in having the inhibitory effect of $\mathrm{XO}[28,29]$.

In terms of psyllium, like allopurinol, this medicinal plant will be able to act naturally as good scavenger and due to strong action of its antioxidant constituents to hinder the formation of free radicals including superoxide anion and hydrogen peroxide. Since allopurinol drug, from one side, through the inhibition of XO enzyme leads to the reduced levels of uric acid, and superoxide anions and on another side by prevention of converting hypoxanthine to xanthine would be able to attenuate uric acid level accordingly the hydrogen peroxide radical cannot be formed and/or reduced. Therefore, it sounds psylium can synergistically potent the power of inhibitory effects allpourinol on XO enzyme (Figure 3).

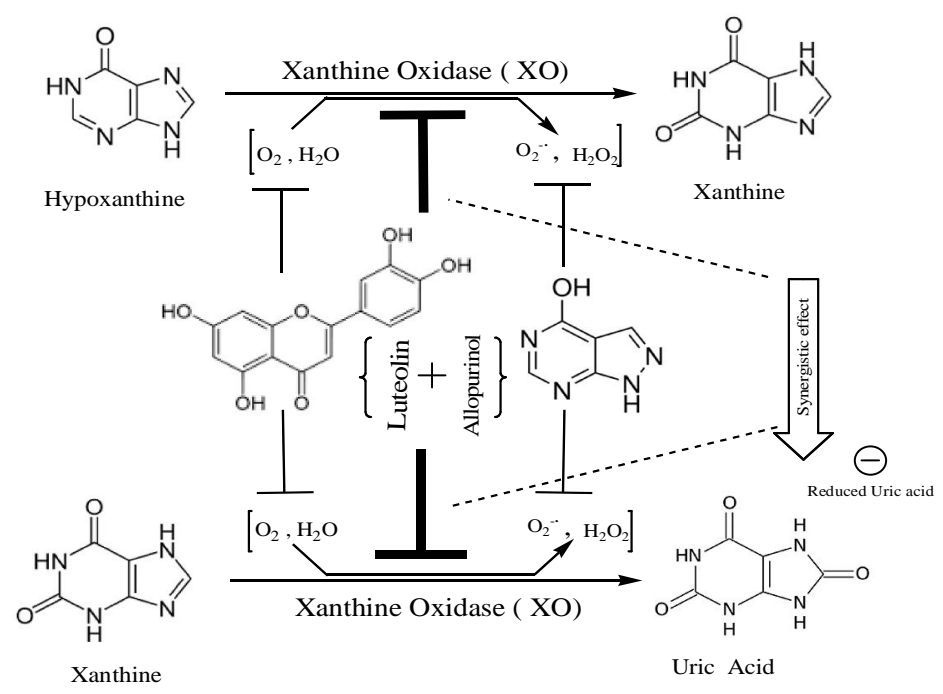

Figure 3. The different pathways for representing the probable mechanisms involving in Xanthine Oxidase enzyme (XO) inhibition through allopurinol, luteolin ( the most significant flavonoid in psyllium plant) and the concomitant use of allopurinol and psyllium in hyperuricemic patient.

\section{CONCLUSION}

Synergetic effect of psyllium on strong inhibition of superoxide and hydrogen peroxide radicals, allegedly related to some special polyphenol compounds (luteolin flavonoid) present in psyllium constituents, leads to lowering the increased levels of uric acid, urea, and 
creatinine in this patient. This study can help us to use some medicinal plants like psyllium, as a strong potential inhibitor of XO enzyme, in conjunction with synthetic drugs for better controlling of increased serum levels of some biochemical parameters such as uric acid, urea, and creatinine in patients representing these similar symptoms.

\section{ACKNOWLEDGEMENT}

Authors are obliged to appreciate the pathobiology laboratory of Farabi Hospital and also the cooperation carried out by the patient. The authors declare that there is no conflict of interest.

\section{REFERENCES}

1. Kunle OF, Egharevba HO, Ahmadu PO. Standardization of herbal medicines- A review. Int J Biodvers Conserv 2012; 4(3): 101-12.

2.Wu Y, Ou-Yang JP, Wu K, Wang Y, Zhou YF, Wen CY. Hypoglycemic effect of Astragalus polysaccharide and its effect on PTP1B. Acta Pharmacol Sin 2005; 26 (3): 345 - 52.

3. Jalilzadeh-Amin G, Maham M. Antidiarrheal activity and acute oral toxicity of Mentha longifolia L. essential oil. Avicenna J Phytomed 2015; 5(2):128-37.

4. Ebadollahinatanzi A, Arabrahmatipor G. The protective effects resulting from a combination of three medicinal plants on liver injury due to carbamazepine drug: A case report. Toxicol Lett 2016; 258S:S105-6.

5. Ebadollahi-Natanzi A, Hajar H, Arab-Rahmatipour G. Determination of total phenolic content and free radical scavenging activity of total extract from the plant Rorippa sylvestris. Iran J Pharm Res 2014; 13(2): 35-6.

6. Arab-Rahmatipour G, Hajar H, Arab-Rahmatipour $\mathrm{M}$, Moradi $\mathrm{H}$. The study of anti-inflammatory effects of lavender, eucalyptus and walnut oil extract compounds. Iran J Pharm Res 2016; 15:478.

7. Ebadollahi Natanzi A, Ghahremani MH, MonsefEsfahani HR, Minaei B, Nazarian H, Sabzevari O. An experimental model for study of the hepatoprotective activity of Nasturtium officinale (Watercress) against acetaminophen toxicity using in situ rat liver system. Eur J Sci Res 2009;38(4):556-64.

8. Ebadollahi Natanzi AR, Ghahremani M, Esfehani HM, Minaei M, Nazarian H, Sabzevari O. Evaluation of antihepatotoxic effect of watercress extract and its fractions in rats. Int $\mathbf{J}$ Pharmacol 2010; 6(6): 896-902.
9. Pittler M, Ernst E. Complementary therapies for reducing body weight: a systematic review.Int $\mathbf{J}$ Obes 2005; 29(9): 1030-8.

10. Pacher P, Nivorozhkin A, Szabó C. Therapeutic effects of xanthine oxidase inhibitors: renaissance half a century after the discovery of allopurinol. Pharmacol Res 2006; 58 (1): 87-114.

11. Chung WH, Wang CW, Dao RL. Severe cutaneous adverse drug reactions. J Dermatol 2016; 43 (7): 758-66.

12. Gliozzi M, Malara N, Muscoli S, Mollace V. The treatment of hyperuricemia. Int J Cardiol 2016; 213:23-7.

13. Haidari F, Keshavarz SA, Rashidi MR, Mahboob SA, Eshraghian MR, Shahi MM. Effects of quercetin and kaempferol versus allopurinol on serum uric acid levels, biomarkers of oxidative stress and hepatic xanthine oxidase/xanthine dehydrogenase activity in hyperuricemic rats .Pharm Sci 2009; 14 (4):301- 9.

14. Zargari A. Medical plants. 6th ed. Tehran: Tehran University Publication; 1997.p.193-205.

15. Libster M. Herb guide for nurses. Delmar, Thomson Learning. Inc USA. 2002:450-7.

16. Rodriguez-Moran M, Guerrero-Romero F, Lazcano-Burciaga G. Lipid and glucose lowering efficacy of Plantago psyllium in type II diabetes. J Diabetes Complications 1998; 12(5):273-8.

17. Sierra M, Garcia JJ, Fernandez N, Diez MJ, Calle AP. Therapeutic effects of psyllium in type 2 diabetic patients. Eur J Clin Nutr 2002; 56(9):83042.

18. Levinson DJ, Becker MA. Clinical gout and the pathogenesis of hyperuricemia. In: McCarty DJ, Koopman WJ, editors. arthritis and allied conditions. Philadelphia: Lea \& Febiger; 1993.p.1773-805.

19. Ziai SA, Larijani B, Akhoondzadeh S, Fakhrzadeh $\mathrm{H}$, Dastpak A, Bandarian F, et al. Psyllium decreased serum glucose and glycosylated hemoglobin significantly in diabetic outpatients. J Ethnopharmacol 2005;102(2):202-7.

20. Nguyen MTT, Awale S, Tezuka Y, Tran QL, Watanabe H, Kadota S. Xanthine oxidase inhibitory activity of Vietnamese medicinal plants. Biol Pharm Bull 2004; 27(9): 1414- 21.

21. Strazzullo P, Puig JG. Uric acid and oxidative stress: relative impact on cardiovascular risk. Nutr Metab Cardiovasc Dis 2007; 17(6): 409- 14.

22. Maia L, Duarte RO, Freire AP, Moura JJG, Mira L. NADH oxidase activity of rat and human liver xanthine oxidoreductase: potent role in superoxide production. J Biol Inorg Chem 2007; 12(6):77787.

23. Nguyen MTT, Awale S, Tezuka Y, Ueda J Y, Tran Q. Kadota S. Xanthine oxidase inhibitors from the 
flowers of Chrysanthemum sinense. Planta Medica 2006;72(1):46-51.

24. Ebadollahinatanzi A, Moghadasi H. Hydrogen peroxide scavenging activity of two different infusions made from black tea. Toxicol lett 2016(258):S192-S3.

25. Chiang LC, Chiang W, Chiang MY, Ng LT, Lin CC. Antileukemic activity of selected natural products in Taiwan. Am J Chin Med 2003; 31(1): $37-46$.

26. Tewari D, Anjum N, Tripathi YC. Phytochemistry and pharmacology of plantago ovata: a natural source of laxative medicine. World J Pharmaceut Res 2014;3(9):361-72.
27. Bayless TM, Hanauer SB. Advanced Therapy of Inflammatory Bowel Disease: Ulcerative Colitis: PMPH-USA; 2011.p. 735-44.

28. Van Hoorn DE, Nijveldt RJ, Van Leeuwen PA, Hofman Z, M'Rabet L, De Bont DB, et al. Accurate prediction of xanthine oxidase inhibition based on the structure of flavonoids. Eur J Pharmacol 2002;451(2):111-8.

29. Cos P, Ying L, Calomme M, Hu JP, Cimanga K, Van Poel B, et al. Structure- activity relationship and classification of flavonoids as inhibitors of xanthine oxidase and superoxide scavengers. J Nat Prod 1998;61(1):71-6. 